\title{
Continuous methane concentration measurements at the Greenland ice sheet-atmosphere interface using a low-cost, low-power metal oxide sensor system
}

\author{
Christian Juncher Jørgensen ${ }^{1}$, Jacob Mønster ${ }^{2}$, Karsten Fuglsang ${ }^{2}$, and Jesper Riis Christiansen ${ }^{3}$ \\ ${ }^{1}$ Department of Bioscience, Arctic Environment, Aarhus University, Roskilde, 4000, Denmark \\ ${ }^{2}$ FORCE Technology, Brøndby, 2605, Denmark \\ ${ }^{3}$ Department of Geoscience and Natural Resource Management, University of Copenhagen, Frederiksberg, \\ Copenhagen, 1958, Denmark
}

Correspondence: Christian Juncher Jørgensen (cjj@bios.au.dk)

Received: 3 December 2019 - Discussion started: 20 December 2019

Revised: 23 April 2020 - Accepted: 10 May 2020 - Published: 22 June 2020

\begin{abstract}
In this paper, the performance of a low-cost and low-power methane $\left(\mathrm{CH}_{4}\right)$ sensing system prototype based on a metal oxide sensor (MOS) sensitive to $\mathrm{CH}_{4}$ is tested in a natural $\mathrm{CH}_{4}$-emitting environment at the Greenland ice sheet (GrIS). We investigate if the MOS could be used as a supplementary measurement technique for monitoring $\mathrm{CH}_{4}$ emissions from the GrIS with the scope of setting up a $\mathrm{CH}_{4}$ monitoring network along the GrIS. The performance of the MOS is evaluated on the basis of simultaneous measurements using a cavity ring-down spectroscopy (CRDS) reference instrument for $\mathrm{CH}_{4}$ over a field calibration period of approximately $100 \mathrm{~h}$. Results from the field calibration period show that $\mathrm{CH}_{4}$ concentrations measured with the MOS are in very good agreement with the reference CRDS. The absolute concentration difference between the MOS and the CRDS reference values within the measured concentration range of approximately $2-100 \mathrm{ppm} \mathrm{CH}_{4}$ was generally lower than $5 \mathrm{ppm}$ $\mathrm{CH}_{4}$, while the relative concentration deviations between the MOS and the CRDS were generally below $10 \%$. The calculated root-mean-square error (RMSE) for the entire field calibration period was $1.69 \mathrm{ppm}(n=37140)$. The results confirm that low-cost and low-power MOSs can be effectively used for atmospheric $\mathrm{CH}_{4}$ measurements under stable water vapor conditions. The primary scientific importance of the study is that it provides a clear example of how the application of low-cost technology can enhance our future understanding on the climatic feedbacks from the cryosphere to the atmosphere.
\end{abstract}

\section{Introduction}

Constraining the various sources and sinks in the global methane $\left(\mathrm{CH}_{4}\right)$ budget is becoming an increasingly important parameter in mitigating climate change (Saunois et al., 2016). The Arctic is generally considered a major global emitter of $\mathrm{CH}_{4}$ to the atmosphere, but significant uncertainty exists as to the seasonal dynamics and strength of both $\mathrm{CH}_{4}$ sources and $\mathrm{CH}_{4}$ sinks from both terrestrial and marine environments as well as the cryosphere (Callaghan et al., 2011; Emmerton et al., 2014; Juncher Jørgensen et al., 2015; Pirk et al., 2017; Zona et al., 2016). A previously unknown source of $\mathrm{CH}_{4}$ emission to the atmosphere was recently identified in which $\mathrm{CH}_{4}$ is emitted from meltwater originating in the subglacial domain of the Greenland ice sheet (GrIS) (Christiansen and Jørgensen, 2018; Lamarche-Gagnon et al., 2018; Wadham et al., 2019). The spatiotemporal coverage of the new $\mathrm{CH}_{4}$ source is yet to be determined, and the overall climatic importance of this new component in the Arctic $\mathrm{CH}_{4}$ budget is still unknown. Future studies are needed in order to assess the overall climatic significance of this source of $\mathrm{CH}_{4}$ emission from the cryosphere to the atmosphere. The current state of knowledge on the $\mathrm{CH}_{4}$ exchange from Greenland is inherently limited by the remoteness of many field sites, following high expedition cost and limitations to the spatial coverage and temporal duration of field measurements. Adding to this is the financial and logistical challenges of bringing high-precision analyzers into the field, namely keeping them powered, running, and shielded in the harsh environments of- 
ten encountered in the Arctic. Thus, there is substantial potential and need to develop low-power techniques and measurement systems that can perform reliable autonomous $\mathrm{CH}_{4}$ concentration measurements. The emergence of low-cost and low-power sensor technology in recent years provides an opportunity to overcome many of current restraints on obtaining continuous field measurements from a wide range of natural $\mathrm{CH}_{4}$-emitting systems (wetlands, ice sheets, marine gas seeps, lakes, permafrost) and expand the network of continuous measurements in remote areas, maximizing our understanding of these systems and minimizing the risk of losing valuable analytical equipment.

Low-cost metal oxide sensors (MOSs) have been widely used for sensing various gases under atmospheric conditions (Wang et al., 2010). However, MOSs have significant obstacles to their direct use as air quality monitors, as their output signal is influenced by the concentrations of both the target and interfering gases as well as the temperature and humidity effects (Masson et al., 2015; Sohn et al., 2008). Other known challenges to the use of MOSs are baseline drift over time, caused by either changes in the heat output of the sensing element or poisoning of the sensor surface (Peterson et al., 2017).

In recent years, investigations into the performance of $\mathrm{CH}_{4}$-sensitive MOSs for the measurement of atmospheric $\mathrm{CH}_{4}$ have been made under both natural and controlled conditions (van den Bossche et al., 2017; Eugster and Kling, 2012; Penza et al., 2015). These studies have been prompted by an increased interest in finding effective methods to quantify $\mathrm{CH}_{4}$ emissions to the atmosphere from both natural systems and man-made systems such as landfills or biogas production plants. Using sensor-specific post-processing to compensate for variations in relative humidity and air temperature, the previous studies have demonstrated a high potential for the low-cost and low-power monitoring of $\mathrm{CH}_{4}$ concentrations above the atmospheric background level for various applications and in sensor networks. In the current study, we tested the in situ performance of a $\mathrm{CH}_{4}$-sensitive MOS (Figaro TGS2611-E00) against a state-of-the-art cavity ring-down spectrometer (CRDS) for $\mathrm{CH}_{4}$ (Ultraportable Greenhouse Gas Analyzer, Los Gatos Research, Inc.) to measure $\mathrm{CH}_{4}$ concentrations in the air expelled from a subglacial meltwater outlet at GrIS. This was done to assess the MOS's potential for serving as a sensing element for future studies of $\mathrm{CH}_{4}$ emissions from the subglacial domain under the Greenland ice sheet.

\section{Materials and methods}

\subsection{Field site and instrumentation}

The study site is located on the southern flank of the Isunnguata Sermia Glacier at the western margin of the GrIS $\left(67^{\circ} 09^{\prime} 16.40^{\prime \prime} \mathrm{N}, 50^{\circ} 04^{\prime} 08.48^{\prime \prime} \mathrm{W}\right)$ at an elevation of
$450 \mathrm{~m}$ a.s.l. (Fig. 1). At a small subglacial meltwater discharge outlet in this area, we performed measurements of $\mathrm{CH}_{4}$ concentrations in the subglacial air expelled from naturally occurring caves carved out by meltwater below the ice sheet. The measurements were done in the period between 22 and 26 June 2018. A more detailed description of the study site at the GrIS is given in Christiansen and Jørgensen (2018).

To sample the subglacial air the sampling tube was attached to an aluminum pole inserted approximately $5 \mathrm{~m}$ into an ice cave (Fig. 2a). The inlet of the sampling tube was connected to a $120 \mathrm{~mL}$ water trap. Humidity and temperature of the subglacial air were measured every $10 \mathrm{~s}$ using a combined sensor (S-THB-M008, Onset, USA; resolution $\left.0.02{ }^{\circ} \mathrm{C}, 0.1 \% \mathrm{RH}\right)$ mounted at the tip of the aluminum pole inserted into the cave. The data were recorded using a datalogger (U30, Onset, USA).

Real-time reference concentration ( $\mathrm{ppm}$ ) measurements of $\mathrm{CH}_{4}$, carbon dioxide $\left(\mathrm{CO}_{2}\right)$, and water vapor $\left(\mathrm{H}_{2} \mathrm{O}\right)$ were obtained using a CRDS (Ultraportable Greenhouse Gas Analyzer, Los Gatos Research, USA). The inlet port of the CRDS was connected to the subglacial sampling point via a sampling tube $(50 \mathrm{~m}$ length, inner diameter of $4 \mathrm{~mm}$, and total volume of $630 \mathrm{~mL}$ ) which was zip-tied to the aluminum pole. The flow of the sample gas from the subglacial sampling point to the measurement cell in the CRDS was obtained via the analyzer's internal diaphragm pump $\left(800 \mathrm{~mL} \mathrm{~min}^{-1}\right)$. The outlet port of the CRDS was connected in series via a $1 \mathrm{~m}$ plastic tube to a metal can enclosure $(400 \mathrm{~mL})$, where the lid had been removed (Fig. 2b). The prototype $\mathrm{CH}_{4}$ sensing system (MOS) was placed in the metal enclosure, where the short serial tube connector ensured a rapid flushing of the headspace in which the $\mathrm{CH}_{4}$ measurements with the MOS were made. Due to the non-destructive sampling principle of the CRDS and the rapid flushing of the headspace volume in the enclosure with the MOS system (2 times per minute), the concentration of $\mathrm{CH}_{4}$ is estimated to be virtually identical at the same time step for the MOS and the CRDS during the entire field calibration period (22 to 26 July 2018).

Following the field calibration test of approximately $100 \mathrm{~h}$, the MOS system was left in the field as an autonomous monitoring system. For this autonomous measurement period, the CRDS was replaced by a $12 \mathrm{~V}$ diaphragm pump (Thomas pumps, 1410VD DC) with a constant air flow of approximately $3 \mathrm{~L} \mathrm{~min}^{-1}$ attached to the common sample tube, with similar connection of the pump inlet and outlet to the CRDS ports. During this period the MOS system was powered by $12 \mathrm{~V} \mathrm{LiFePO}_{4}$ batteries connected to solar panels and a voltage regulator, placed in a waterproof case and buried under a pile of rocks to minimize the impact of sunlight-induced temperature variations in the sensor system.

\subsection{The MOS system}

The MOS system (Fig. 2c) consists of a microcontroller (Arduino Uno) and datalogger shield (Deek-Robot data- 

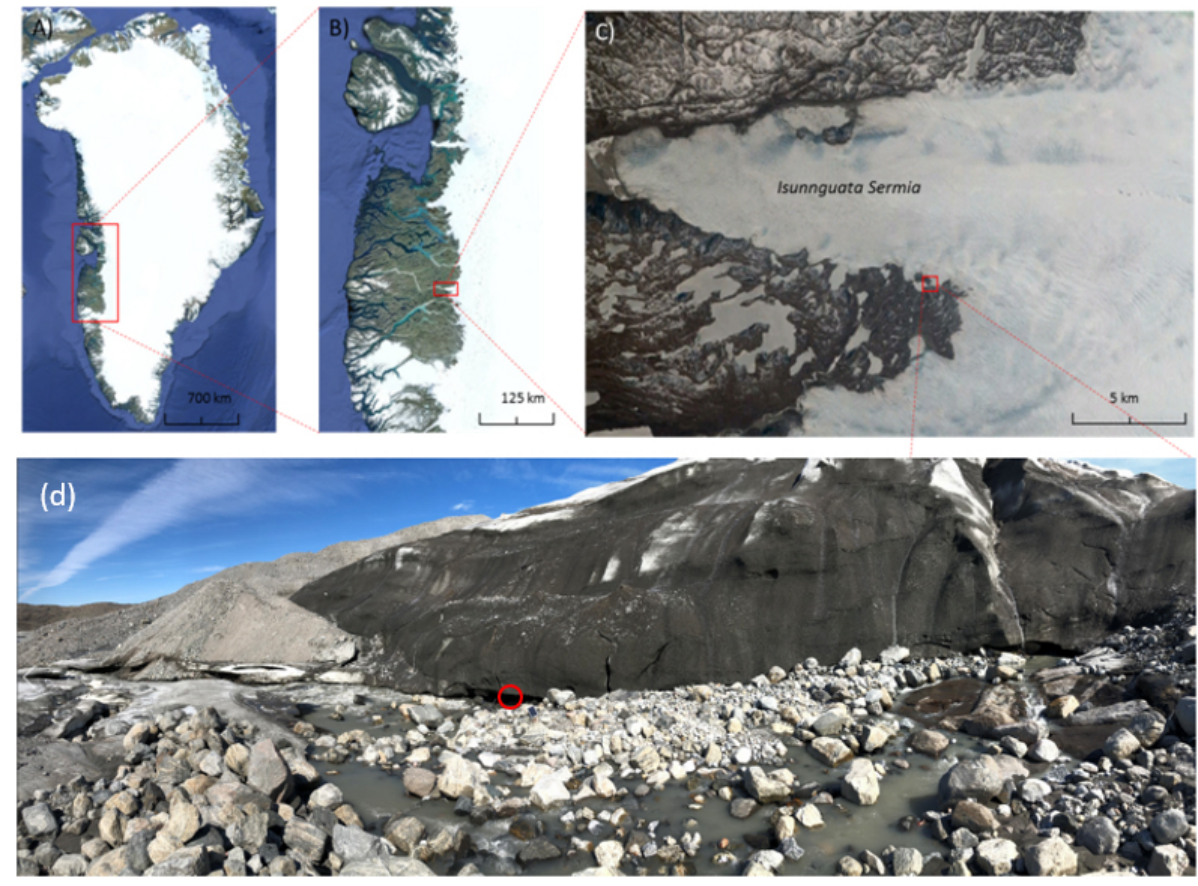

Figure 1. Overview of the sampling location at Isunnguata Sermia Glacier at the western margin of the Greenland ice sheet during June 2018. (a) Location of sampling region the island of Greenland, (b) regional location of the outlet glacier, (c) location of the meltwater outlet at Isunnguata Sermia, and (d) local sample location, with investigated subglacial cavity marked with red circle. Source of (a, b, c): () Google Earth, https://earth.google.com/web/ (last access: 23 April 2020).
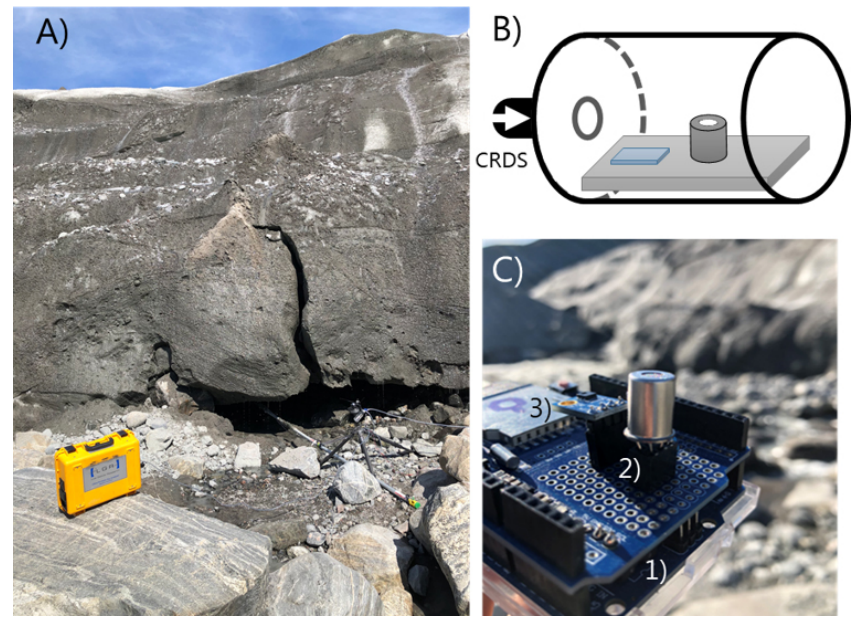

Figure 2. (a) Close-up of air-filled cavity below the Greenland ice sheet next to the lateral meltwater outlet. The aluminum pole extends approximately $5 \mathrm{~m}$ into the cavity and holds the common inlet tube and the temperature and humidity smart sensor. (b) Conceptual diagram of the MOS system which was connected in series to the outlet port of the CRDS analyzer. (c) Close-up of the boardmounted MOS and temperature-humidity micro-sensor. The MOS system consisted of (1) a microcontroller, (2) datalogger shield holding metal oxide $\mathrm{CH}_{4}$ sensor, and (3) an additional temperaturerelative humidity micro-sensor. logging shield V1.0) holding the board-mounted metal oxide $\mathrm{CH}_{4}$ sensor (Figaro TGS2611-E00) and an additional temperature-relative humidity micro-sensor (GY-21 HTU21). The final prototype was assembled in the laboratory at Aarhus University. The logging frequency of the CRDS and MOS was 1 and $10 \mathrm{~s}$, respectively. The $\mathrm{CH}_{4-}$ sensitive MOS consists of a tin(IV) oxide $\left(\mathrm{SnO}_{2}\right)$ semiconductor, which has low conductivity in clean air. In the presence of $\mathrm{CH}_{4}$, the sensor's conductivity increases depending on the gas concentration in the air (Kumar et al., 2009). A simple electrical circuit converts the changes in conductivity at the sensing element as the gas concentrations vary into a change in output voltage across the voltage divider (see Fig. 3). Both the heater and the sensing circuit of the MOS were powered by the $5 \mathrm{~V}$ regulated output of the Arduino Uno. The analogue output of the MOS was connected to the 10 bit analogue input on the Arduino Uno using a $10 \mathrm{k} \Omega$ precision load resistor in the voltage divider.

\subsection{Laboratory calibration of the MOS}

In preparing for the field test of the $\mathrm{CH}_{4}$ sensing system prototype, the MOS was performance tested and calibrated in a controlled laboratory environment to evaluate the response time to variations in methane concentration in the concentration range $0-100 \mathrm{ppm}^{-\mathrm{CH}_{4}}$ at three different levels of relative humidity $(37 \pm 2 \%, 55 \pm 3 \%$, and $76 \pm 3 \%)$. 


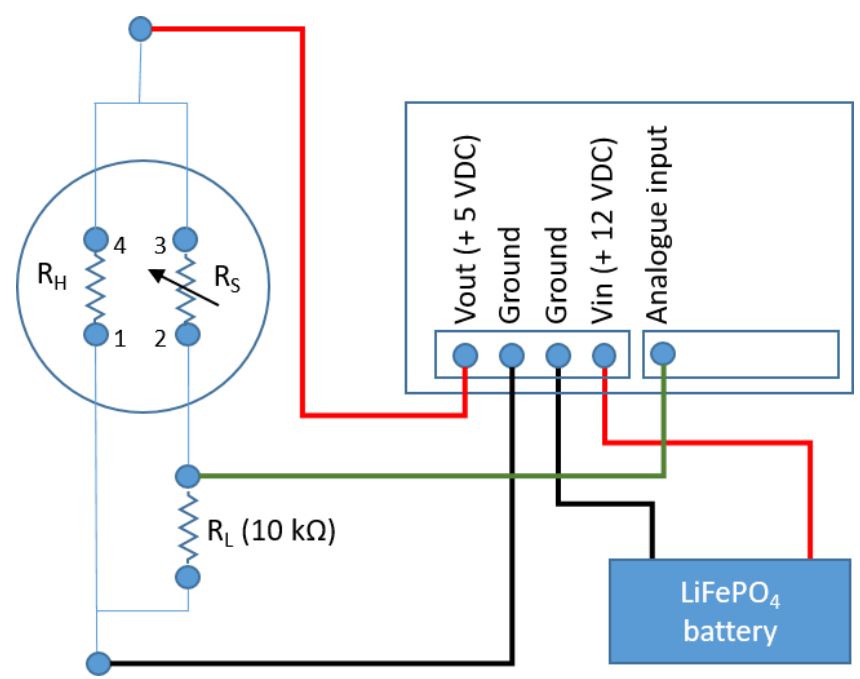

Figure 3. Simplified schematic of the metal oxide sensor (MOS) system consisting of a TGS2611-E00 with pin 3 and 4 connected to the $5 \mathrm{~V}$ output of the Arduino Uno, pin 1 connected to ground, and pin 2 connected to the analogue input of the Arduino Uno and a $10 \mathrm{k} \Omega$ load resister, which also connects to ground.

Synthetic air $\left(80 \% \mathrm{~N}_{2}\right.$ and $\left.20 \% \mathrm{O}_{2}\right)$ was used as zero gas for the laboratory test into which various concentrations of a $\mathrm{CH}_{4}$-containing span gas were mixed using a HovaCAL calibration gas generator (IAS GmbH, Germany). After mixing of the zero gas and span gas, the calibration gas was humidified using a water-filled impinger (van den Bossche et al., 2017). At each humidity level, the output voltage from the MOS was logged using a Campbell CR1000 datalogger at a $2 \mathrm{~s}$ sampling frequency. A preprogrammed calibration step sequence was used for all three humidity levels, consisting of time steps of $10 \mathrm{~min}$ each in which the sensor was exposed to either zero gas or a calibration gas mixture in the applied the concentration range in an alternating step pattern (Fig. 4). The temperature in the laboratory, zero gas, mixed calibration gas, and water in the impinger was kept constant at around $22{ }^{\circ} \mathrm{C}$ throughout the laboratory calibration test.

The sensor resistance $\left(R_{0}\right)$ at exposure to the $\mathrm{CH}_{4}$-free reference gas can be calculated at each of the three different humidity levels according to Eq. (1):

$R_{0}=\frac{V_{\mathrm{C}} \cdot R_{\mathrm{L}}}{V_{\mathrm{OUT}}}-R_{\mathrm{L}}$

where $V_{\mathrm{C}}$ is the circuit voltage (i.e., $5 \mathrm{~V} \mathrm{DC}$ ), $R_{\mathrm{L}}$ is the load resistance $\left(10 \mathrm{k} \Omega\right.$ ), and $V_{\text {OUT }}$ is the measured output voltage (see also Eugster and Kling, 2012, for further description).

The sensor resistance at various calibration gas concentrations $\left(R_{\mathrm{S}}\right)$ at different concentration steps in the calibration sequence can also be calculated using Eq. (1) for each of the three humidity levels (i.e., Rs replaces $R_{0}$ in Eq. 1). For the tested type of MOS, the sensor resistance ratio $\left(R_{\mathrm{S}} / R_{0}\right)$ between the sensor resistance at a given concentration level

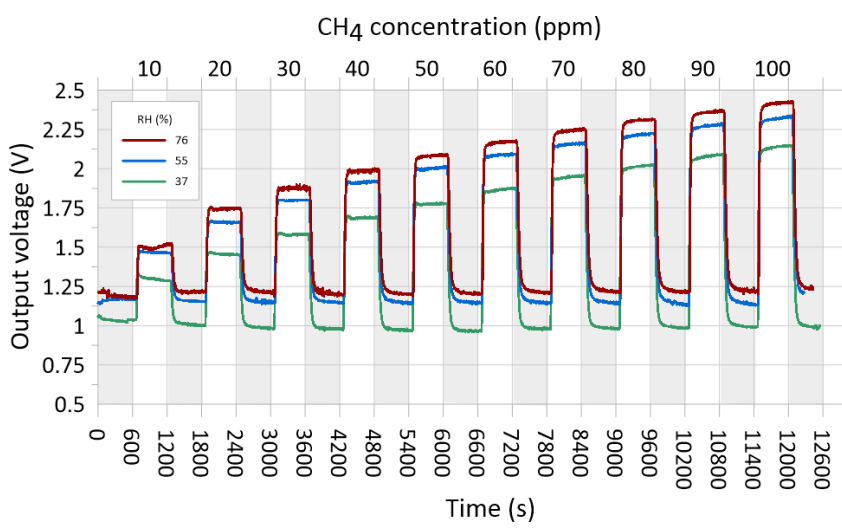

Figure 4. Outlet voltages of the MOS during laboratory step calibration at stabilized levels of relative humidity $(37 \pm 2 \%, 55 \pm 3 \%$, and $76 \pm 3 \%$ ) in both the zero and span gas at alternating concentration of $\mathrm{CH}_{4}$ in the calibration gas between 10 and $100 \mathrm{ppm} \mathrm{CH}_{4}$. Each time step lasted $10 \mathrm{~min}$, and sequences with grey shading show time periods where the sensor was exposed to $\mathrm{CH}_{4}$-free zero gas.

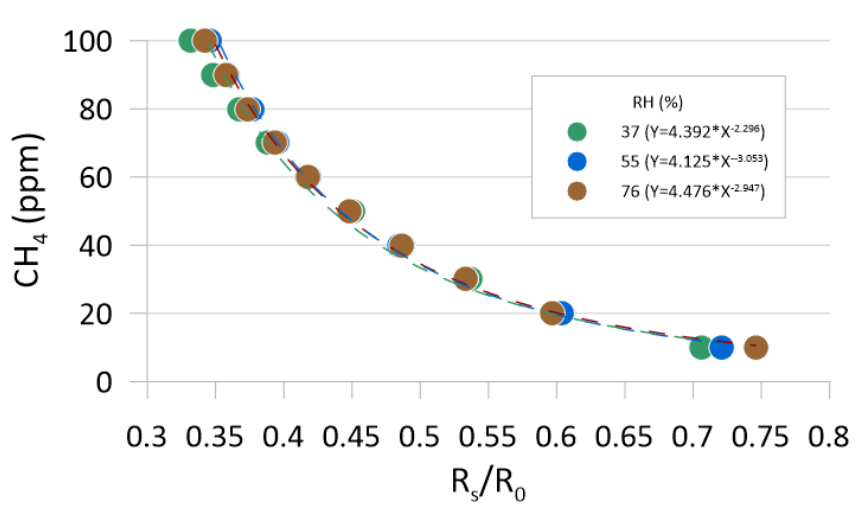

Figure 5. Resistance ratio of MOS as three levels of relative humidity at $\mathrm{CH}_{4}$ concentration levels between 10 and $100 \mathrm{ppm} \mathrm{CH}_{4}$ in humidified synthetic air.

(Rs) and the sensor resistance at the reference level $\left(R_{0}\right)$ are inversely proportional to the absolute $\mathrm{CH}_{4}$ concentration and can be modeled using, for example, a power fit (Fig. 5).

\subsection{Field calibration of the MOS}

Field calibration of the MOS was done at the meltwater outlet at the Greenland ice sheet by simultaneous measurements of the same air mass by the MOS system and a state-of-the-art CRDS in the configuration described above (Sect. 2.1). For the calculation of the average ambient sensor resistance $\left(R_{0^{*}}\right)$ using Eq. (1), the atmospheric background concentration of $\mathrm{CH}_{4}$ of the air (approximately $1.9 \mathrm{ppm}$ ) close to the ice sheet was used, in the absence of a controlled and humidified zero gas. Exact measurements of temperature and humidity of this air mass are not available, but $T$ and $\mathrm{RH}$ are estimated to fall within the range of $1-4{ }^{\circ} \mathrm{C}$ and $90 \%-100 \% \mathrm{RH}$. The output value of the MOS under these conditions was then used to 


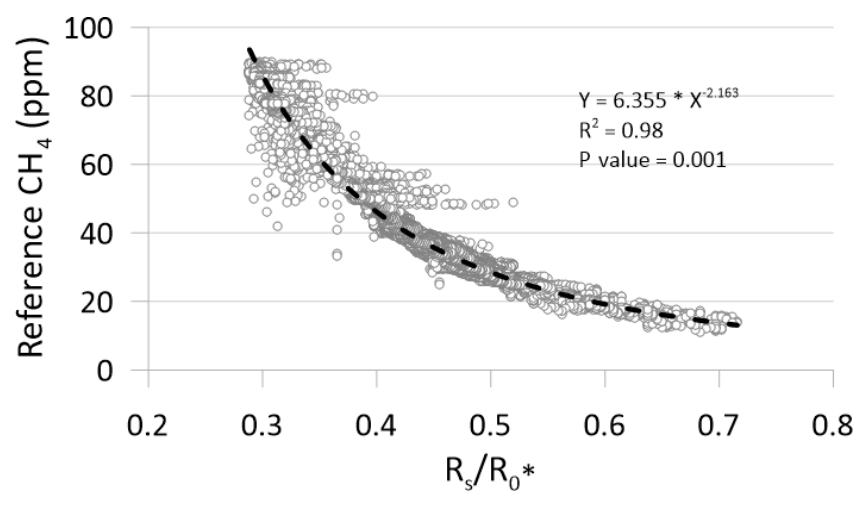

Figure 6. Regression plot of calculated MOS resistance ratio $R_{\mathrm{S}} / R_{0}$ * vs. the reference in situ $\mathrm{CH}_{4}$ concentrations from the CRDS $(n=37140)$.

establish the resistance ratio $\left(R_{\mathrm{S}} / R_{0^{*}}\right)$ vs. $\mathrm{CH}_{4}$ concentration field calibration function for the MOS (Fig. 6).

\subsection{Data processing}

In order to compensate for potential effects of microturbulent mixing of subglacial air with atmospheric air observed with the CRDS (Christiansen and Jørgensen, 2018). which occur at a faster frequency than the 10 s sampling interval of the MOS (see also Sect. 3.3), the measured raw time-series data from the MOS were smoothed using simple exponential smoothing according to Eq. (2):

$s_{t}=\alpha x_{t}+(1-\alpha) s_{t-1}$ for $t>0$,

where $s_{t}$ is the smoothed $\mathrm{CH}_{4}$ concentration value (ppm), $\alpha$ is the smoothing factor, and $s_{t-1}$ is the previous smoothed $\mathrm{CH}_{4}$ concentration value (ppm). At time zero $(t=0)$, the $s_{t}$ is equal to the first unsmoothed raw $\mathrm{CH}_{4}$ value of the MOS. The optimum value for $\alpha$ was determined using the Microsoft Excel solver by minimizing the total average root-mean-square error (RMSE) between the raw data from the MOS and the simultaneous concentration measurement of the CRDS. Results show an optimal value of 0.042 , which was used for both the CRDS and MOS data series (Fig. 7).

\section{Results and discussion}

\subsection{Laboratory calibration test of the MOS}

Figure 3 shows the relationship between the resistance ratio $\left(R_{\mathrm{S}} / R_{0}\right)$ for the step test at three regulated humidity levels, where Ro is calculated for each humidity level based on the average voltage output of the sensor in the time steps where it was exposed to the $\mathrm{CH}_{4}$-free synthetic air. It is observed that a near-identical response function can be obtained across the three different water vapor concentrations in the air, as long as the water concentration of the zero gas is the same as in
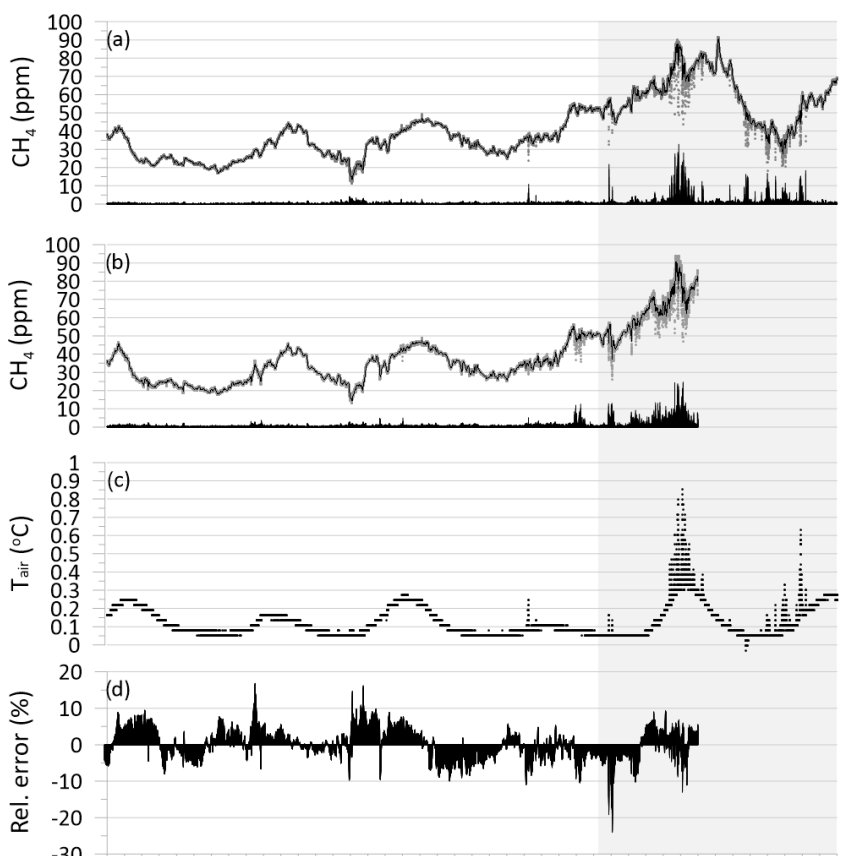

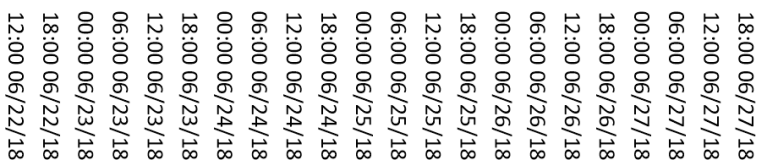

Figure 7. (a) Grey dots show raw $\mathrm{CH}_{4}$ concentration from the cavity ring-down spectrometer (CRDS). Black line shows CRDS $\mathrm{CH}_{4}$ concentration values following exponential smoothing. Black bars show absolute error between raw and smoothed values. (b) Grey dots show calculated raw $\mathrm{CH}_{4}$ concentration from metal oxide sensor (MOS). Black line shows MOS $\mathrm{CH}_{4}$ concentration values following exponential smoothing. Black bars show absolute error between raw and smoothed values. (c) Black dots show temperature of air in subglacial cavity. (d) Black bars show the relative error in percentage between $\mathrm{MOS}_{\text {smooth }}$ and $\mathrm{CRDS}_{\text {smooth }}$ divided by the $\mathrm{CRDS}_{\text {smooth }}$ concentration. Grey background shading indicates period with higher observed turbulence at the margin of the GrIS. Temporal resolution is $10 \mathrm{~s}$.

the span gas. Based on existing knowledge of the expected air temperature variations at the in situ sampling point at the GrIS (Christiansen and Jørgensen, 2018), the humidity calibration was only carried out at a single temperature in this study. However, variations in the ambient air temperature are also expected to have a linear scaling effect for the type MOS system tested in this study (Bastviken et al., 2020; van den Bossche et al., 2017).

\subsection{Field calibration of the metal oxide sensor}

The measured $R_{\mathrm{S}} / R_{0^{*}}$ ratios per time step over the field calibration period were converted into absolute $\mathrm{CH}_{4}$ concentrations using the regression statistics of the applied power model (Fig. 6). A total of 37140 data points are included in the regression model for converting the $R_{\mathrm{S}} / R_{0^{*}}$ ratios to 
$\mathrm{CH}_{4}$ concentrations. Inclusion of data points from the microturbulent periods produces a noisy visualization of the calibrations data at higher $\mathrm{CH}_{4}$ concentration levels (Fig. 6). However, this apparent noise is primarily a visual artifact that does not have significance for the underlying calibration statistics, which shows excellent statistical agreement between the independent and dependent variables $\left(R^{2}=0.98\right.$; $p$ value: 0.001 ). While the same regression model is used for both the laboratory calibration and field calibration, significant deviation in the model parameters is observed between the laboratory calibration as a group and the field calibration. The reason for this difference is unknown, but a possible explanation could be the potential difference in input heater voltage for the MOS (i.e., pin 1 and 4 in Fig. 3), since variations in the input heater voltage have been reported to affect the $\mathrm{CH}_{4}$ concentration measurements (van den Bossche et al., 2017). In the laboratory test, the heater circuit of the MOS was supplied by the $5 \mathrm{~V}$ regulated output from the CR1000 datalogger, whereas the heater circuit was supplied from the Arduino Uno's 5 V regulated output. Future tests should aim to investigate if the differences between the results from the laboratory and field calibration can be minimized by using the same type of datalogger and identical power supply (FX rechargeable lithium ion battery pack) both in the laboratory and in the field. Results from this type of test could reveal if field calibration for each individual MOS system is needed, similar to the approach in Bastviken et al. (2020), or if batch calibrations of several identical MOS systems can be performed in the laboratory without the need for timeconsuming field calibration.

\subsection{Time-series plot of $\mathrm{CH}_{4}$ concentration from reference CRDS and MOS}

Due to the dynamic environment at the margin of the GrIS, the physical configuration of the sampling point will vary over the melt season as well as on an inter-annual basis. In our previous study, high-frequency variations in $\mathrm{CH}_{4}$ concentrations in the subglacial air were observed in a downward-draping curve style, where a high concentration plateau was interrupted by rapid decreases in $\mathrm{CH}_{4}$ concentration (Christiansen and Jørgensen, 2018). This pattern was interpreted to be an effect of micro-turbulent and wind-driven dilution of the sample gas in the ice cave by atmospheric air with a $\mathrm{CH}_{4}$ concentration of approximately $1.9 \mathrm{ppm}$. In the current study, exponential smoothing of the raw values is used to compensate for the potential effects of physical disturbance of the sample gas caused by wind-driven turbulent mixing of atmospheric background air at the subglacial sample point. Also, temporal smoothing can compensate for some of the sensor-specific variation in response time, improving the pairwise measurement comparability between the CRDS and the MOS. According to the manufacturer, the CRDS is specified to have a response time of less than $1 \mathrm{~Hz}$, while the response time of the MOS is expected to be slower.
The time-series plot of the raw and exponentially smoothed $\mathrm{CH}_{4}$ data from the CRDS $\left(\mathrm{CRDS}_{\text {smooth }}\right)$ is shown together with the pairwise error between the raw data and the smoothed data (Fig. 7a). Similarly, the time-series plot of the raw and exponentially smoothed $\mathrm{CH}_{4}$ data from the MOS $\left(\mathrm{MOS}_{\mathrm{smooth}}\right)$ is shown together with the pairwise error between the raw data and the smoothed data (Fig. 7b). It is generally observed that over the first $4 \mathrm{~d}$ of the calibration test, very few differences are observed between the raw data $\mathrm{CH}_{4}$ concentration and the smoothed $\mathrm{CH}_{4}$ concentrations for both $\mathrm{CRDS}_{\text {smooth }}$ and $\mathrm{MOS}_{\text {smooth, with absolute er- }}$ rors below 5 ppm (Fig. 7a, b). At the end of the field calibrations, more errors are observed following the larger spread in $\mathrm{CH}_{4}$ concentration measurements of both the CRDS and the MOS. CRDS analyzers across different brands and manufacturers generally perform very consistently and have a highly linear measurement response across the effective concentration range, without any tendencies for increasing analytical error with increasing gas concentrations (Brannon et al., 2016). Fluctuations in $\mathrm{CH}_{4}$ concentrations in the subglacial air were also observed in Christiansen and Jørgensen (2018) using a CRDS from another manufacturer (G4301 GasScouter, Picarro Inc.). These variations were attributed to the dynamic and micro-turbulent environment in the subglacial cavity where the gas concentrations were measured and are likely produced by air movement generated by the shear stress of the running meltwater as well as turbulent intrusion of atmospheric air generated by shifting wind speeds at the measurement location at the ice margin.

According to the field notes for the current study, a shift in overall wind regime took place during 25 June 2018, where the weather shifted from calm and sunny conditions to more windy conditions dominated by strong catabatic easterly winds coming off the GrIS. A best estimate of the overall time period where more windy conditions occurred during the field calibration period is indicated with the grey background in Fig. 7. Unfortunately, no direct measurements of wind movement were made during the fieldwork period at the location. Measurements of air temperature at the sample inlet point in the subglacial cavity (Fig. 7c) show that an initial period with diurnal temperature variations of approximately 0.1 to $0.2{ }^{\circ} \mathrm{C}$ was followed by a period with more fluctuating temperature variations of up to $+0.6^{\circ} \mathrm{C}$. The period with higher variability corresponds to the period where higher wind speeds predominate and the deviations between the raw and smoothed $\mathrm{CH}_{4}$ are the greatest. The higher variability in air temperature measurements during the more windy weather is interpreted as being a product of more turbulent wind conditions right at the margin of the GrIS and opening to the subglacial cavity, by which higher amounts of warmer atmospheric air with an approximate $\mathrm{CH}_{4}$ concentration of approximately $1.9 \mathrm{ppm}$ are introduced into the subglacial cavity. The introduction of these atmospheric air masses results in short-term temperature increases as well as dilution of the subglacial $\mathrm{CH}_{4}$ concentra- 
tion in the cavity producing the more variable $\mathrm{CH}_{4}$ concentration patterns observed in both the CRDS and MOS raw data. In the absence of direct measurements of wind speed and micro-turbulence at the margin of the ice, rapid variations in air temperature at the sample inlet point with an amplitude greater than $0.2^{\circ} \mathrm{C}$ appear to be a reasonable indicator or proxy for micro-turbulent dilution and physical disturbance of the source signal, which can effectively be filtered out by the application of exponential smoothing.

The relative error between each $\mathrm{MOS}_{\text {smooth }}$ and

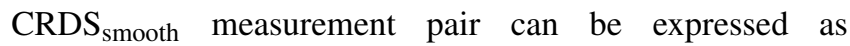
the percentage that the difference constitutes compared to the reference CRDS concentration (i.e., $\left.\mathrm{MOS}_{\text {smooth }}-\mathrm{CRDS}_{\text {smooth }} / \mathrm{CRDS}_{\text {smooth }} \cdot 100\right)$. It is seen that the pairwise relative error between $\mathrm{MOS}_{\text {smooth }}$ and $\mathrm{CRDS}_{\text {smooth }}$ shows similar non-systematic variations in both the calm weather and windy time period, with relative errors typically below $\pm 10 \%$ (Fig. 7d). This result shows both that the accuracy of the $\mathrm{CH}_{4}$ concentration measured by the MOS is in close agreement with the reference CRDS and that the exponential smoothing effectively compensates for short-term physical disturbances at the measurement point. The result also indicates that no systematic drift or over- or underestimation is apparent when comparing $\mathrm{MOS}_{\text {smooth }}$ to $\mathrm{CRDS}_{\text {smooth }}$ over the $100 \mathrm{~h}$ field calibration period (Fig. $7 \mathrm{~b}$ ). When considering the magnitude of the absolute errors between the raw and smoothed $\mathrm{CH}_{4}$ concentration for both the CRDS and the MOS together with the temporal pattern in the development of the relative error, it shows that the high-frequency concentration fluctuations measured with the MOS are most likely the product of physical disturbances at the measurement point (primary sampling error) and not an analytical error introduced by the MOS itself (secondary sampling error).

As a supplement to the pairwise error comparison, average time-series performance statistics for the difference between the $\mathrm{MOS}_{\text {smooth }}$ and $\mathrm{CRDS}_{\text {smooth }}$ time series can be calculated for the full-field calibration period as well for the non-turbulent time period with limited observed physical disturbance at the sampling point (Table 1). RMSEs of the non-turbulent and full time series are approximately 1.3

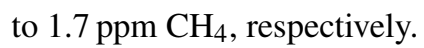

\subsection{Post-correction and cross-interference evaluation}

One of the main obstacles previously reported concerning the use of MOSs for monitoring of gases in ambient air is the possible effect of variations in air temperature and humidity in the sampling environment (Bastviken et al., 2020; Eugster et al., 2019; Masson et al., 2015; Sohn et al., 2008). Different approaches exist to compensate for this potential measurement error and are related to post-correcting for variations in temperature and humidity, based on either generic temperature and humidity dependency curves supplied by the sensor company (Eugster and Kling, 2012). This is achieved by per-
Table 1. Statistics for the calculated differences between the smoothed MOS and smoothed CRDS data series in both the nonturbulent time period and full-field calibration period. The unit for error and difference values is parts per million (ppm).

\begin{tabular}{lrr}
\hline Statistics: MOS $_{\text {smooth }}-$ CRDS $_{\text {smooth }}$ & Non-turbulent & Full series \\
\hline Mean bias error (MBE) & 0.09 & -0.05 \\
Mean absolute error (MAE) & 1.08 & 1.29 \\
Root-mean-square error (RMSE) & 1.35 & 1.69 \\
Maximum negative difference & -3.96 & -11.83 \\
Maximum positive difference & 5.04 & 5.91 \\
Observations & 28501 & 37140 \\
\hline
\end{tabular}

forming sensor calibrations under controlled levels of temperature and humidity in the laboratory (van den Bossche et al., 2017) or by field calibration (Bastviken et al., 2020).

Measurements from the air-filled cavity under the GrIS document a very stable sampling environment with a relative humidity throughout the sampling period of close to $100 \%$ RH (data not shown) and only minor air temperature variations between approximately $0.05^{\circ} \mathrm{C}$ during the night and $0.25^{\circ} \mathrm{C}$ at midday (Fig. $7 \mathrm{~d}$ ). Because of these stable and well-buffered environmental conditions, no post-corrections due to variations in temperature and relative humidity are deemed necessary for this particular sampling environment.

Observed variations in maximum air temperature in the subglacial cavity correspond to field observation of the time of the day when maximum meltwater discharge occurs. We assume that the observed temperature pattern reflects the impact of thermal heat diffusion from this running meltwater to the air immediately above but would need direct measurements of the daily variations in meltwater temperature to verify this assumption.

The emitted $\mathrm{CH}_{4}$ may originate from thermogenic and/or biogenic sources below the GrIS. If the primary source of $\mathrm{CH}_{4}$ is thermogenic, the emission may also be accompanied by more complex hydrocarbons, including ethane $\left(\mathrm{C}_{2} \mathrm{H}_{6}\right)$, while this will not be the case if the source is biogenic (Hopkins et al., 2016). Since the MOS used in the study is non-selective to $\mathrm{CH}_{4}$ due to its basic principle of operation (Eugster and Kling, 2012; Wang et al., 2010), the presence of other hydrocarbons such as ethanol $\left(\mathrm{C}_{2} \mathrm{H}_{6} \mathrm{O}\right)$, isobutene $\left(\mathrm{C}_{4} \mathrm{H}_{10}\right)$, and potentially also other low-molecular-weight alkanes could potentially cause cross interference with the $\mathrm{CH}_{4}$ measurement. It follows that if the source of the $\mathrm{CH}_{4}$ that is emitted for the subglacial domain originates in thermogenic natural gas reservoirs under the GrIS, the other non$\mathrm{CH}_{4}$ hydrocarbons could potentially affect the measurements performed by the MOS while being undetected by the CRDS. However, since the magnitudes and temporal patterns in $\mathrm{CH}_{4}$ concentrations are similar in both the CRDS and MOS, it is assumed that the gases emitted from the subglacial domain are primarily $\mathrm{CH}_{4}$ and $\mathrm{CO}_{2}$, with very limited potential for cross interference from other hydrocarbon gases. Also, iso- 
topic analysis of the emitted $\mathrm{CH}_{4}$ and $\mathrm{CO}_{2}$ in LamarcheGagnon et al. (2018) as well as unpublished data from this study have shown that the emitted $\mathrm{CH}_{4}$ is dominantly of microbial origin and has isotopic similarity to $\mathrm{CH}_{4}$ produced by anaerobic decomposition of organic carbon in wetlands. We therefore assume that there is no need for any post-correction of the $\mathrm{CH}_{4}$ concentrations measured by the MOS in this type of environment due to lack of cross interference from other hydrocarbon gases.

\subsection{Autonomous $\mathrm{CH}_{4}$ monitoring using MOS system}

The combined time period in which $\mathrm{CH}_{4}$ concentrations were measured can be divided into three separate periods depending on the analytical devices used, namely period 1, corresponding to the field calibration period where both the CRDS and MOS were in operation (approximately $100 \mathrm{~h}$ ), period 2, where only the CRDS was in operation (approximately $24 \mathrm{~h}$ ), and period 3, where only the MOS was in operation (Fig. 8). Continuous $\mathrm{CH}_{4}$ data from period 3 exist for the period from 27 June to 15 July 2018. When comparing the combined $\mathrm{CH}_{4}$ concentration curves from all three periods, it is observed that $\mathrm{CRDS}_{\text {smooth }}$ and $\mathrm{MOS}_{\text {smooth }}$ follow each other as described above (Fig. 7). CRDS $_{\text {smooth }}$ data for period 2 fill the data gap between the MOS measurement of period 1 and 3 , where the start concentration data of $\mathrm{MOS}_{\text {smooth }}$ are similar to the concentration level where the $\mathrm{CRDS}_{\text {smooth }}$ measurements end. Due to the nature of the study design and difficult access to the remote field site at the GrIS, the accuracy and precision of $\mathrm{MOS}_{\text {smooth }}$ cannot be evaluated for the period 3, where only the MOS system was operating. However, the pattern in which subglacial $\mathrm{CH}_{4}$ concentrations varied and the estimated minimum and maximum values appear to be similar to the values of the calibration period. When comparing the complete time period of this study to, for example, Eugster and Kling (2012), no significant sensor drift is expected over the monitoring time period. Additional and extended fieldwork at the GrIS with repeated calibration at the end of the field deployment period is needed to quantify the potential sensor drift as well as stability range over longer timescales (Eugster et al., 2019). Nonetheless, the observed performance of the MOS during the calibration period with parts-per-million-level accuracies and subsequent trouble-free operation running as an autonomous unit shows that this type of low-cost and low-power $\mathrm{CH}_{4}$ sensing system has great potential for the further development and refinement of a greater sensor network at representative meltwater outlets at the Greenland ice sheet.

The next steps and lessons learned from this study deal with the further development of the low-power system for actual $\mathrm{CH}_{4}$ emission measurements, which involves measurements of air volume and meltwater discharge as well as continuous measurements of the dissolved $\mathrm{CH}_{4}$ in the meltwater, similar to Lamarche-Gagnon et al. (2018). Also, optimizing the positioning of gas-sensing equipment at the measurement

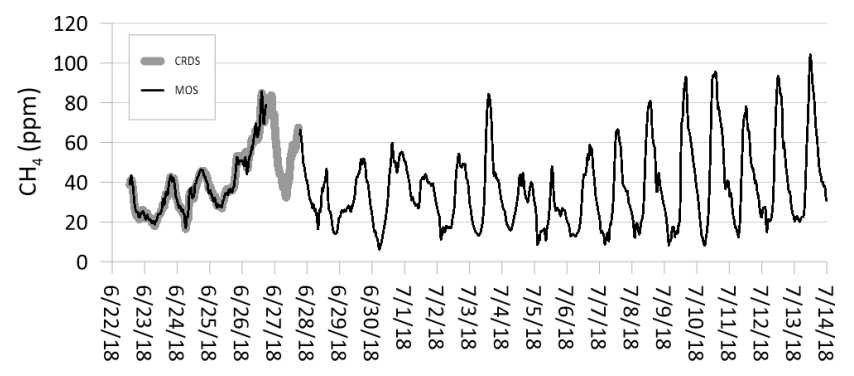

Figure 8. Smoothed time-series measurements of $\mathrm{CH}_{4}$ at the Greenland ice sheet using both the cavity ring-down spectroscopy (CRDS) reference monitor and the metal oxide sensor (MOS). Temporal resolution is $10 \mathrm{~s}$.

point should be done to reduce the potential physical disturbances due to micro-turbulence and intrusion of atmospheric air in the subglacial cavity. Furthermore, an improved adjustment scheme should be developed to account for the dynamic meltback of the ice margin over the melt season, which requires either manual or automated sample point relocation to keep the sampling point at an optimal physical location. Finally, more work is needed to test the modification to the systems that are needed to establish a universal calibration curve in the laboratory so that the need for field calibration with the reference CRDS can be eliminated (see also Bastviken et al., 2020; Eugster et al., 2019).

\section{Conclusions}

Recent discoveries at the Greenland ice sheet (GrIS) have revealed a cryospheric source of $\mathrm{CH}_{4}$ from the subglacial domain under the ice to the atmosphere that has been overlooked so far. Development of low-power $\mathrm{CH}_{4}$ monitoring systems based on low-cost metal oxide sensors (MOSs) could enable the development of a sensor network at representative meltwater outlets at the GrIS which could significantly improve the fundamental understanding of the phenomena's climatic importance. In the current study, the performance of a metal oxide sensor sensitive to $\mathrm{CH}_{4}$ was tested in an air-filled cavity at the edge of the Greenland ice sheet over an initial field calibration period of approximately $100 \mathrm{~h}$. Simultaneous measurements by both cavity ring-down spectroscopy (CRDS) and a low-cost MOS using a common inlet show good agreement between the MOS and the CRDS over time under the stable environmental conditions under the ice. Exponential smoothing of the raw data from both the CRDS and MOS effectively removes high-frequency concentration variations induced by physical disturbance of the air in the subglacial cavity under more turbulent wind conditions at the margin of the ice sheet. Based on concentration values of the smoothed CRDS and MOS data, the pairwise measurement errors were generally below $\pm 5 \mathrm{ppm} \mathrm{CH}_{4}$ between the MOS and the CRDS reference value. Pairwise relative er- 
rors were generally below $\pm 10 \%$ between the MOS and the CRDS reference value. The RMSE for the entire field calibration period was $\pm 1.69 \mathrm{ppm} \mathrm{CH}_{4}$. If only data for the nonturbulent time period were evaluated, the RMSE was reduced to $\pm 1.35 \mathrm{ppm} \mathrm{CH}_{4}$. Due to the ice-buffered sampling environment in the air-filled cavity under the Greenland ice sheet, no post-corrections for variations in air temperature, humidity, or cross interference from other hydrocarbon gases were needed for the MOS measurements. Combined with measurement of airflow and meltwater discharge, the measurement of $\mathrm{CH}_{4}$ concentrations can be used for determination of the mass flux of $\mathrm{CH}_{4}$ to the atmosphere. The study demonstrates a clear potential for expanded monitoring of spatial and temporal variation in $\mathrm{CH}_{4}$ emissions from the subglacial domain of the Greenland ice sheet using low-cost and lowpower MOS.

Data availability. Original data can be accessed by e-mail to the corresponding author Christian Juncher Jørgensen (cjj@bios.au.dk).

Author contributions. CJJ and JRC designed and carried out the field experiments. CJJ, JMO, and KFU planned and carried out the laboratory calibrations. CJJ and JRC prepared the paper, with contributions from all co-authors.

Competing interests. The authors declare that they have no conflict of interest.

Acknowledgements. The laboratory test of MOSs was performed by FORCE Technology.

Financial support. This research has been supported by the Brødrene Hartsmanns Fond (Udledning af metan til atmosfæren fra gletchere (project no. A32524)) and the Danish Agency for Innovation (A4 Den Danske Renluftsektor).

Review statement. This paper was edited by Daniela Famulari and reviewed by three anonymous referees.

\section{References}

Bastviken, D., Nygren, J., Schenk, J., Parellada Massana, R., and Duc, N. T.: Technical note: Facilitating the use of low-cost methane $\left(\mathrm{CH}_{4}\right)$ sensors in flux chambers - calibration, data processing, and an open source make-it-yourself logger, Biogeosciences Discuss., https://doi.org/10.5194/bg-2019-499, in review, 2020.

Brannon, E. Q., Moseman-valtierra, S. M., Rella, C. W., Martin, R. M., Chen, X., and Tang, J.: Evaluation of laser- based spectrometers for greenhouse gas flux measurements in coastal marshes, Limnol. Oceanogr.-Meth., 14, 466-476, https://doi.org/10.1002/lom3.10105, 2016.

Callaghan, T. V., Johansson, M., Key, J., Prowse, T., Ananicheva, M., and Klepikov, A.: Feedbacks and Interactions: From the Arctic Cryosphere to the Climate System, AMBIO, 40, 75-86, https://doi.org/10.1007/s13280-011-0215-8, 2011.

Christiansen, J. R. and Jørgensen, C. J.: First observation of direct methane emission to the atmosphere from the subglacial domain of the Greenland Ice Sheet, Scientific Reports, 8, 16623, https://doi.org/10.1038/s41598-018-35054-7, 2018.

Emmerton, C. A., St. Louis, V. L., Lehnherr, I., Humphreys, E. R., Rydz, E., and Kosolofski, H. R.: The net exchange of methane with high Arctic landscapes during the summer growing season, Biogeosciences, 11, 3095-3106, https://doi.org/10.5194/bg-113095-2014, 2014.

Eugster, W. and Kling, G. W.: Performance of a low-cost methane sensor for ambient concentration measurements in preliminary studies, Atmos. Meas. Tech., 5, 1925-1934, https://doi.org/10.5194/amt-5-1925-2012, 2012.

Eugster, W., Laundre, J., Eugster, J., and Kling, G. W.: Long-term reliability of the Figaro TGS 2600 solid-state methane sensor under low Arctic conditions at Toolik lake, Alaska, Atmos. Meas. Tech. Discuss., https://doi.org/10.5194/amt-2019-402, in review, 2019.

Hopkins, F. M., Kort, E. A., Bush, S. E., Ehleringer, J. R., Lai, C. T., Blake, D. R., and Randerson, J. T.: Spatial patterns and source attribution of urban methane in the Los Angeles Basin, J. Geophys. Res., 121, 2490-2507, https://doi.org/10.1002/2015JD024429, 2016.

Juncher Jørgensen, C., Lund Johansen, K. M., Westergaard-Nielsen, A., and Elberling, B.: Net regional methane sink in High Arctic soils of northeast Greenland, Nat. Geosci., 8, 20-23, https://doi.org/10.1038/ngeo2305, 2015.

Kumar, R., Imam, S. A., and Khan, M. R.: A Critical Review of Taguchi Gas Sensor for the Detection of VOC's, MASAUM Journal Of Reviews and Surveys, 1, 177-183, available at: https://www.researchgate.net/profile/Rajesh _Kumar529/publication/239280207_A_CRITICAL_REVIEW _OF_TAGUCHI_GAS_SENSOR_FOR_THE_DETECTION_ _OF_VOC'S/links/59bab980aca272aff2d012f8/A-CRITICALREVIEW-OF-TAGUCHI-GAS-SENSOR-FOR-THE-

DETECTION-OF-VOCS.pdf (last access: 23 April 2020), 2009.

Lamarche-Gagnon, G., Wadham, J. L., Lollar, B. S., Arndt, S., Fietzek, P., Beaton, A. D., Tedstone, A. J., Telling, J., Bagshaw, E. A., Hawkings, J. R., Kohler, T. J., Zarsky, J. D., Mowlem, M. C., Anesio, A., and Stibal, M.: Greenland melt drives continuous export of methane from its bed, Nature, 565, 73-77, https://doi.org/10.1038/s41586-018-0800-0, 2018.

Masson, N., Piedrahita, R., and Hannigan, M.: Approach for quantification of metal oxide type semiconductor gas sensors used for ambient air quality monitoring, Sensor. Actuat. B-Chem., 208, 339-345, https://doi.org/10.1016/J.SNB.2014.11.032, 2015.

Penza, M., Suriano, D., Cassano, G., Pfister, V., Amodio, M., Trizio, L., Brattoli, M., and De Gennaro, G.: A case-study of microsensors for landfill air-pollution monitoring applications, Urban Climate, 14, 351-369, https://doi.org/10.1016/j.uclim.2014.09.002, 2015. 
Peterson, P., Aujla, A., Grant, K., Brundle, A., Thompson, M., Vande Hey, J., and Leigh, R.: Practical Use of Metal Oxide Semiconductor Gas Sensors for Measuring Nitrogen Dioxide and Ozone in Urban Environments, Sensors, 17, 1653, https://doi.org/10.3390/s17071653, 2017.

Pirk, N., Mastepanov, M., López-Blanco, E., Christensen, L. H., Christiansen, H. H., Hansen, B. U., Lund, M., Parmentier, F.J. W., Skov, K., and Christensen, T. R.: Toward a statistical description of methane emissions from arctic wetlands, Ambio, 46, 70-80, https://doi.org/10.1007/s13280-016-0893-3, 2017.

Saunois, M., Bousquet, P., Poulter, B., Peregon, A., Ciais, P., Canadell, J. G., Dlugokencky, E. J., Etiope, G., Bastviken, D., Houweling, S., Janssens-Maenhout, G., Tubiello, F. N., Castaldi, S., Jackson, R. B., Alexe, M., Arora, V. K., Beerling, D. J., Bergamaschi, P., Blake, D. R., Brailsford, G., Brovkin, V., Bruhwiler, L., Crevoisier, C., Crill, P., Covey, K., Curry, C., Frankenberg, C., Gedney, N., Höglund-Isaksson, L., Ishizawa, M., Ito, A., Joos, F., Kim, H.-S., Kleinen, T., Krummel, P., Lamarque, J.-F., Langenfelds, R., Locatelli, R., Machida, T., Maksyutov, S., McDonald, K. C., Marshall, J., Melton, J. R., Morino, I., Naik, V., O'Doherty, S., Parmentier, F.-J. W., Patra, P. K., Peng, C., Peng, S., Peters, G. P., Pison, I., Prigent, C., Prinn, R., Ramonet, M., Riley, W. J., Saito, M., Santini, M., Schroeder, R., Simpson, I. J., Spahni, R., Steele, P., Takizawa, A., Thornton, B. F., Tian, H., Tohjima, Y., Viovy, N., Voulgarakis, A., van Weele, M., van der Werf, G. R., Weiss, R., Wiedinmyer, C., Wilton, D. J., Wiltshire, A., Worthy, D., Wunch, D., Xu, X., Yoshida, Y., Zhang, B., Zhang, Z., and Zhu, Q.: The global methane budget 2000-2012, Earth Syst. Sci. Data, 8, 697-751, https://doi.org/10.5194/essd-8-697-2016, 2016.
Sohn, J. H., Atzeni, M., Zeller, L., and Pioggia, G.: Characterisation of humidity dependence of a metal oxide semiconductor sensor array using partial least squares, Sensor. Actuat. B-Chem., 131, 230-235, https://doi.org/10.1016/J.SNB.2007.11.009, 2008.

van den Bossche, M., Rose, N. T., and De Wekker, S. F. J.: Potential of a low-cost gas sensor for atmospheric methane monitoring, Sensor. Actuat. B-Chem., 238, 501-509, https://doi.org/10.1016/j.snb.2016.07.092, 2017.

Wadham, J. L., Hawkings, J. R., Tarasov, L., Gregoire, L. J., and Spencer, R. G. M.: Ice sheets matter for the global carbon cycle, Nat. Commun., 10, 3567, https://doi.org/10.1038/s41467019-11394-4, 2019.

Wang, C., Yin, L., Zhang, L., Xiang, D., and Gao, R.: Metal oxide gas sensors: sensitivity and influencing factors, Sensors-Basel, 10, 2088-2106, https://doi.org/10.3390/s100302088, 2010.

Zona, D., Gioli, B., Commane, R., Lindaas, J., Wofsy, S. C., Miller, C. E., Dinardo, S. J., Dengel, S., Sweeney, C., Karion, A., Chang, R. Y.-W., Henderson, J. M., Murphy, P. C., Goodrich, J. P., Moreaux, V., Liljedahl, A., Watts, J. D., Kimball, J. S., Lipson, D. A., and Oechel, W. C.: Cold season emissions dominate the Arctic tundra methane budget, P. Natl. Acad. Sci. USA, 113, 40-45, https://doi.org/10.1073/pnas.1516017113, 2016. 